\title{
Encontros e desencontros entre a psicologia e a pedagogia nos processos de inclusão escolar
}

\begin{abstract}
Resumo: Este artigo traz reflexões sobre a atuação de profissionais da saúde e da educação no contexto da política de inclusão em escolas brasileiras, considerando a seguinte questão: qual de fato é o papel do pedagogo e do psicólogo no processo de inclusão escolar? A partir do relato de duas experiências, em diferentes projetos de inclusão escolar de crianças, uma envolvendo estudantes do curso de Psicologia em uma universidade do Rio de Janeiro e outra com estudantes do curso de Pedagogia, em Minas Gerais, a reflexão recai na discussão sobre as problemáticas que atravessam as práticas no fazer cotidiano de escolas tanto nos seus tensionamentos quanto vislumbrando possibilidades de atuação e de interlocução entre os profissionais de diferentes campos disciplinares, o da pedagogia e o da psicologia. A partir da perspectiva da psicologia histórico-cultural e da epistemologia da prática, a análise das experiências apresentadas aponta que investir na articulação do trabalho do pedagogo e do psicólogo se mostra fundamental na perspectiva de que um traz subsídios para o trabalho do outro sem superposições ou subalternizações.
\end{abstract}

Palavras-chave: Inclusão escolar. Psicologia. Pedagogia.

\section{Introdução}

Diante das políticas de inclusão escolar no Brasil, recentemente implementadas, as escolas têm demandado, com frequência, um profissional da área da psicologia para lidar com os impasses que surgem com a chegada de um novo perfil de estudante. O professor/ pedagogo, sentindo-se despreparado para lidar com esses novos alunos, passa, então, a acreditar que o psicólogo será o profissional mais capacitado para efetivar o processo de inclusão nesta instituição. Mas, qual de fato é o papel do pedagogo e do psicólogo no processo de inclusão escolar?

Este artigo apresenta algumas reflexões sobre a atuação de profissionais tanto da saúde quanto da educação no contexto da política de inclusão em escolas brasileiras, tomando como parâmetro duas diferentes experiências: uma de estágio/pesquisa envolvendo estudantes do curso de Psicologia em uma universidade do Rio de Janeiro e outra, de ensino, com estudantes do curso de Pedagogia em Minas Gerais.

Aproximações e(ou) distanciamentos entre as experiências servirão como analisadores/balizadores de como a política de inclusão vem ocorrendo nos bastidores das instituições escolares
Luciana Ferreira Barcellos Universidade Federal de São João del-Rei lucianafbarcellos@gmail.com Maria Jaqueline Grammont Machado de Araújo Universidade Federal de São João del-Rei

jaquelinedegrammont@gmail.com 
e o que fazem revelar sobre o cenário educacional brasileiro de forma mais ampla.

A inclusão escolar se institui como política pública de modo abrangente, mas ganha materialidade de variadas formas em razão das especificidades de cada instituição de ensino, sobretudo considerando a disparidade socioeconômica existente entre as instituições públicas, e entre estas e as privadas, além das diferenças entre os projetos político-pedagógicos de cada instituição.

Na construção do processo de inclusão na escola, o que se tem verificado, em algumas escolas do País, é a construção de estratégias isoladas de enfrentamento e o pouco preparo dos profissionais, tanto da educação como da saúde. Há que se considerar que os desafios de uma educação inclusiva já existiam na educação antes mesmo da implementação oficial da política de inclusão. Quando nos referimos ao "pouco preparo dos profissionais", não se trata de afirmar pouca qualificação ou conhecimento técnico a respeito de síndromes ou formas específicas de atuação com crianças com necessidades especiais. Há outras questões que se colocam em razão da estrutura escolar, no formato e modo de funcionamento, que obstaculizam a eficácia da política de inclusão nas escolas, além de algumas concepções que restringem as possibilidades de respostas efetivas que serão que serão, aqui, objeto de reflexão.

A partir da perspectiva da psicologia histórico-cultural e da epistemologia da prática (TARDIF, 2000), primeiramente, serão apresentadas breves considerações a respeito do cenário da política de educação inclusiva no Brasil e seus efeitos. Posteriormente, serão apresentadas duas experiências e as questões teórico-práticas que mais se destacaram no processo de cada uma: a primeira experiência baseia-se em um projeto de estágio/pesquisa na área de psicologia educacional, em um curso de graduação em Psicologia de uma universidade privada da cidade do Rio de Janeiro, e a segunda, na atuação de bolsistas do curso de Pedagogia no âmbito do Programa de Bolsas de Iniciação Científica (Pibid) de uma universidade federal de Minas Gerais. Reflexões sobre as tensões e possibilidades de diálogo entre esses campos finalizarão esta discussão. 


\section{Considerações sobre a Política de Educação Inclusiva no Brasil e alguns desdobramentos}

Não há como pensar a inclusão, ou qualquer questão que envolva a escola, desvinculada das políticas públicas. Como já dizia Paulo Freire (2002), educar é essencialmente um ato político. Sendo assim, a escola, com sua característica conservadora, como alerta Bourdieu (1989), tem um papel fundamental na manutenção da hierarquia social, sendo, portanto, secularmente seletiva e excludente. Impossível, então, analisar o processo de inclusão desvinculado dessa condição. Por coerência, a análise tem de se pautar na dialética exclusão/inclusão. (SAWAIA, 2011)

Nesse sentido, mais do que abrir a porta da escola para os sujeitos com necessidades especiais, é preciso construir as condições para sua permanência, de forma que eles possam conquistar o lugar de sujeitos de aprendizagem, com processos pedagógicos que potencializem suas condições de apropriação do conhecimento, considerando-se suas diferenças físicas, neurológicas e(ou) sociais.

A política de educação inclusiva no Brasil vem, a partir da sua implementação, convocando as instituições educacionais a construírem estratégias para dar suporte à proposta.

O Ministério da Educação, por intermédio da Secretaria de Educação Especial (MEC/SEESP), apresentou em 2008, a Política Nacional de Educação Especial na Perspectiva da Educação Inclusiva considerando que todos os alunos devem se matricular nos sistemas de ensino, ficando a cargo das escolas o atendimento aos educandos com necessidades especiais. Cabe então à escola, segundo prevê esse documento, assegurar as condições necessárias para que estes sujeitos, sem diferenciação e discriminação, usufruam de uma educação de qualidade. Estariam entre os objetivos da política:

Assegurar a inclusão escolar de alunos com deficiência, transtornos globais do desenvolvimento e altas habilidades/ superdotação, orientando os sistemas de ensino para garantir: acesso ao ensino regular, com participação, aprendizagem e continuidade nos níveis mais elevados do ensino; transversalidade da modalidade de educação especial desde a educação infantil até a educação superior; oferta do atendimento educacional especializado; formação de professores para o atendimento educacional especializado e demais profissionais da educação para a inclusão; participação da família e da comunidade; acessibilidade arquitetônica, nos 
transportes, nos mobiliários, nas comunicações e informação; e articulação intersetorial na implementação das políticas públicas. (BRASIL, 2008)

Para a efetivação desses objetivos, de um modo geral, parte-se de uma perspectiva que pressupõe que a inclusão só se efetivará se as escolas garantirem um conjunto de condições previamente ao ingresso dos estudantes em situação de inclusão. Em outra direção, três aspectos podem ser considerados: 1) a escola precisa assumir o lugar de protagonista, e não de vítima do processo; 2) a política pública deve fornecer investimentos materiais e estruturais para sua efetivação; 3) pouco se conhece a respeito dos sujeitos a serem incluídos, porque estiveram, desde sempre, à margem. São esses os sujeitos que, junto com a sociedade e a escola, podem orientar direções e possíveis caminhos para o enfrentamento das problemáticas.

Na busca de um olhar menos voltado para os obstáculos e mais para o que já houve de avanço, sugere-se a substituição do termo "condições" pelo termo "investimentos". Estes permitem salientar uma potência de realização ou de luta, enfatizando o protagonismo da escola com vistas à efetivação de uma política de caráter, de fato, inclusivo (ARAÚJO, 2015), sendo fundamentais para que ocorram avanços no processo de inclusão escolar.

Esses investimentos, então, necessários ao processo de inclusão da pessoa com necessidades especiais na escola são de ordens material, social e pedagógica, interdependentes e perpassam políticas e práticas; isto é, não são investimentos exclusivos da escola e de seus professores. Consideram-se investimentos materiais a adequação do espaço físico e a aquisição de materiais específicos, tecnológicos ou não, com agilidade, segundo as necessidades reais dos sujeitos da escola. Os investimentos sociais seriam aqueles construídos a partir de políticas públicas, relacionadas tanto com a diminuição do número de estudantes em sala de aula como aqueles mais sistemáticos e complexos, que envolvem a destinação de tempos, espaços e recursos financeiros, para que a escola possa manter uma articulação com a área da saúde e um trabalho conjunto com a família. Os investimentos pedagógicos envolvem questões relacionadas às definições curriculares, gestão escolar, interação aluno-professor.

É nessa direção, na articulação entre saúde e educação, escola e sociedade, e considerando os vários atores sociais implicados, 
direta e(ou) indiretamente, que se propõe analisar de que forma a política de inclusão atravessou, e vem atravessando, as práticas de alguns dos atores sociais que dela participam.

Uma instituição escolar é composta por professores e estudantes e conta também com efeitos da atuação dos profissionais de saúde - psicólogos, médicos e nutricionistas, dentro e(ou) fora da escola -, além de funcionários e familiares. As formações acadêmicas desses diferentes campos de conhecimento/atuação precisam estar alinhadas às práticas desenvolvidas nas instituições escolares. Portanto, as experiências cotidianas das escolas, nas suas dificuldades e estratégias de enfrentamento, precisam servir de dispositivos de análise para a formação universitária tanto de professores quanto de psicólogos educacionais.

Nesse caminho, serão apresentadas as reflexões das professoras pesquisadoras que supervisionaram as duas experiências, uma da Psicologia e outra da Pedagogia, em que alunos e alunas da universidade atuaram na educação básica com crianças em situação de inclusão. Na Psicologia, a atuação dos estudantes universitários se deu como mediadores no processo de inclusão e, na Pedagogia, como bolsistas do Pibid, atuando em turmas com alunos com necessidades especiais. Por isso, povoam este texto vozes de campos distintos que se encontraram profissionalmente com interesses similares e que, passando por diferentes experiências, encontraram consonância, aproximações e ecos nos modos de pensar o contexto de inclusão educacional.

Assim, no decorrer do artigo, será apresentada cada uma dessas experiências de forma específica, para, então, se colocarem em diálogo as reflexões e proposições decorrentes desses processos na intersecção entre os dois campos disciplinares.

\section{Estudantes de Psicologia na função de mediadores escolares: uma experiência do Rio de Janeiro}

Fruto dos desdobramentos da política pública de inclusão no País, algumas escolas privadas regulares do Rio de Janeiro recebem crianças com necessidades especiais, ficando, entretanto, a cargo dos familiares, a contratação desses profissionais para fazerem o acompanhamento cotidiano delas nas escolas, mais especificamente nas salas de aula. Vale salientar que, desde 2015 ficou vedada pela Lei Brasileira de Inclusão da pessoa com deficiência (BRASIL, 
2015), a cobrança de valores adicionais de qualquer natureza pelas instituições privadas.

Esse acompanhamento deveria objetivar o desenvolvimento pedagógico tanto quanto vislumbrar a socialização e a adaptação da criança no novo espaço. Porém, o que se verifica é que a prática da mediação escolar acaba, em algumas situações, sendo apenas uma saída de empregabilidade para estudantes que precisam se manter na universidade, subsidiando custos com alimentação, transporte e outros, independente do curso de formação.

Diante desse cenário, um coletivo de estudantes de Psicologia, já atuantes em escolas exercendo a função de mediação, buscou supervisão na área de Psicologia escolar, de forma a criar um grupo de pesquisa, cujas discussões embasaram as reflexões tematizadas neste artigo, colocando em questão o próprio campo de formação/ prática em Psicologia Educacional. Os encontros aconteceram, ao longo do ano de 2015, semanalmente e eram alternados por discussão de textos e estudos de caso, nos quais os estudantes apresentavam suas estratégias de atuação, impasses e dificuldades no acompanhamento das crianças e na relação dos demais atores, sobretudo familiares e professores.

Se, por um lado, estudantes estariam sendo contratados para exercer atividades que, por conta das demandas de familiares e da escola, se assemelhavam à de meros acompanhantes das crianças - sem reflexão ou construção de estratégias de atuação condizentes com a proposta de inclusão efetiva -, por outro, a convivência cotidiana nas salas de aula permitia que esses alunos tomassem contato com um espaço rico de interações entre diversos atores e com as principais dificuldades e tensionamentos vivenciados por esses sujeitos. Esse convívio cotidiano propiciou reflexões e análises de relevância para a compreensão das problemáticas educacionais.

As discussões realizadas nesse grupo de supervisão deflagraram questionamentos: se alunos de diferentes áreas do conhecimento estariam exercendo a prática de mediadores escolares, qual seria a função desse profissional? Que reflexões a chegada desses mediadores escolares aponta a respeito do modo como a política de inclusão escolar estaria ocorrendo no cotidiano das instituições? De que forma os conhecimentos do campo da Psicologia da Educação poderiam contribuir para auxiliar na execução da política de educação inclusiva? 
Por meio dos encontros de pesquisa/supervisão, foi possível ter contato com as impressões dos mediadores escolares, além de suas dificuldades e apreensões. As experiências possibilitaram reflexões importantes sobre os processos de inclusão/exclusão nos espaços escolarizados, que serão analisadas a seguir.

Uma vez que a experiência de escolarização das crianças, em quaisquer condições, é atravessada pelas relações que estabelecem na escola com os vários atores sociais, então, mediar significa intermediar, estar entre os atores, assumindo um papel na rede de relações dentro e fora do ambiente escolar.

Participar do cotidiano das crianças nas escolas significa vivenciar, de certa maneira, do ponto de vista da criança, a experiência de ingresso em um espaço estrangeiro, sendo afetado e tomando contato com as apreensões e dificuldades enfrentadas por elas no ambiente escolar. Um aspecto de destaque é a construção de vínculos afetivos, de ambas as partes, entre os mediadores e as crianças em situação de inclusão. As angústias e apreensões frente às dificuldades enfrentadas pelas crianças na adaptação em um novo espaço afetam os mediadores, assim como estes produzem efeitos, de ordens variadas, nos processos de subjetivação das crianças com as quais convivem cotidianamente.

"O aprendizado humano pressupõe uma natureza social específica e um processo através do qual as crianças penetram na vida intelectual daquelas que as cercam". (VYGOTSKY, 1984, p. 99) Nesse sentido, cabe colocar em relevo três aspectos da teoria de Vygotsky: a integração entre os elementos cognitivo, afetivo e social como partes constitutivas do desenvolvimento/aprendizagem da criança; a aprendizagem como um processo que ocorre necessariamente na interação social; e a linguagem como ferramenta de mediação entre sujeito e cultura, cuja compreensão da palavra se dá no contexto de uso, numa dimensão intersubjetiva.

Analisando o processo de aprendizagem da criança na interação social, vale considerar que:

Na medida em que o aprendizado desperta vários processos internos de desenvolvimento, e na medida em que estes operam basicamente quando a criança interage com as pessoas de seu ambiente, a qualidade dessas interações ganha uma dimensão de destaque, o que justifica uma análise mais profunda, seja dos aspectos socioculturais na formação da criança, seja da linguagem como mediadora destes aspectos. (JOBIM E SOUZA; KRAMER, 1991, p. 78) 
Tomando como referenciais de análise as perspectivas de Vygotsky (1984), há que se considerar que quaisquer relações produzem efeitos em todos os sujeitos que delas participam. A linguagem, analisada de forma mais ampla, não fica restrita ao registro falado, assim como o sentido da palavra não é estático. Há que se destacar a construção de sentidos que ocorre no momento do ato de comunicação entre os sujeitos, incluindo aspectos como entonação, dimensão afetiva e expressão gestual, entre outros.

Situando a experiência da criança no contexto da instituição escolar, Dayrell (1996) compreende o sentido da escola, sob a ótica da cultura, como um espaço sociocultural, incluindo o dinamismo e o fazer cotidiano de sujeitos concretos, inseridos na história.

No processo de inclusão, as escolas se veem diante da entrada de um novo ator em seu cotidiano, que participa do dia a dia da escola, tendo contato próximo com as crianças em situação de inclusão, com as demais crianças da turma, com outros mediadores escolares e com professores-regentes, ao mesmo tempo, sendo contratados como prestadores de serviços pelas famílias. Nesse contexto, cabe analisar a experiência dos estudantes de Psicologia como mediadores escolares na interlocução com os vários atores sociais.

Em algumas dessas instituições, as famílias das crianças com necessidades especiais se responsabilizam pela contratação dos mediadores, para acompanharem as atividades das crianças durante o período de escolarização. Contudo, assumindo condutas as mais diversas, as famílias orientam e atribuem aos mediadores funções que variam de vigilância da escola, da criança mediada, até funções que se confundem com os papéis a serem desempenhados pelos próprios familiares, como cuidados com higiene e acompanhamento das tarefas em casa.

Alguns "professores" - professores-regentes - sentem-se afetados pela presença desses novos atores participando cotidianamente das suas aulas. Por outro lado, sobrecarregados com o excesso de alunos e frente às exigências de produtividade e, sobretudo, pouco preparados para lidar com a chegada de um novo perfil de alunado, delegam aos mediadores suas funções.

Os diretores são, também, convocados a se posicionar. Alguns deles, a fim de impedir que as famílias delimitem as regras de atuação dos mediadores e, por consequência, interfiram no projeto político-pedagógico, na dinâmica de funcionamento e nas regras 
da escola, passam a realizar reuniões periódicas com eles, estabelecendo funções, direitos e deveres.

Quanto às crianças, há que se salientar que, nas instituições escolares, elas experienciam relações distintas das que vivenciam no interior das famílias. As experiências na escola misturam momentos em que as figuras de autoridade estão presentes e outros em que as crianças encontram mais liberdade de interação entre os pares - recreio e educação física.

As crianças com necessidades especiais que são acompanhadas pelos mediadores escolares passam a ser observadas em todos os momentos de participação na escola. A premissa de que "o mediador deve ser os olhos e ouvidos da família" e de que deve estar presente em todos os espaços de socialização da criança neste espaço acaba por reforçar a noção de "deficiência" vinculada à incapacidade de autonomia das crianças, impossibilitando brechas de escape e construção de subjetivação distantes dos olhares vigilantes dos adultos.

Essas reflexões remetem à concepção de poder proposta por Foucault (1979). Não existiria algo unitário e global chamado poder, mas unicamente formas díspares, heterogêneas, em constante transformação. "O poder não é um objeto natural, uma coisa; é uma prática social, e, como tal, constituída historicamente”. (FOUCAULT, 1979, p. X)

Nessa perspectiva, comportamentos indisciplinados dessas crianças muitas vezes são interpretados como sintomas próprios dos diagnósticos. Porém, podem sinalizar tentativas de escape frente ao excesso de vigilância das crianças, que têm suas diferenças associadas à incapacidade e visíveis pela presença permanente do mediador escolar.

Os diagnósticos das crianças com necessidades especiais acabam sendo usados como justificativa para todos os seus comportamentos e situações de desencaixes. Há que se distinguir o que, de fato, cada diagnóstico limita em termos de desenvolvimento/aprendizagem e o que é próprio de uma criança em um tempo de vida específico e que se constitui na relação com outros atores sociais.

Moraes e Arendt (2010, p. 2), tomando como referência a proposta da teoria ator-rede, apresentam os resultados de pesquisa com pessoas com deficiência visual: com a finalidade de acompanhar "os modos por meio dos quais a deficiência existe, é feita em certos arranjos sociomateriais locais". Os pesquisadores entendem ainda que: 
A deficiência não é o que uma pessoa é nela mesma. Nem tampouco alguma coisa que é produzida por um social que, de fora, do exterior, sobredetermina o indivíduo. Lidar com modos de ordenamento implica tomar o social não como substantivo, mas como verbo, como um processo precário, local, situado; implica ainda colocar o foco tanto na heterogeneidade material quanto na multiplicidade e na complexidade de tais ordenamentos. (MORAES; ARENDT, 2010, p. 2)

Essas questões sinalizam a existência de problemáticas concernentes ao cenário da educação brasileira anteriores às políticas de inclusão nas escolas, mas que a chegada das crianças com necessidades especiais faz visibilizar.

O diálogo entre os diferentes campos disciplinares - sobretudo os campos da Psicologia e da Educação - , é fundamental para a construção de estratégias de enfrentamento coletivas frente aos processos de inclusão/exclusão escolar.

\section{A experiência do Pibid do curso de Pedagogia de uma universidade de Minas Gerais}

O Pibid do curso de Pedagogia de uma universidade pública do estado de Minas Gerais, entre os anos de 2011 e 2013, abordou os processos de inclusão na escola e a formação de professores nessa perspectiva. Assim, a reflexão recaiu sobre as condições e as possibilidades de formação docente para o trabalho na educação básica que tenham alunos em situação de inclusão num processo de reflexão-ação-reflexão (SCHÖN, 1992) entre os saberes construídos pelos alunos do curso de Pedagogia, bolsistas do Pibid, e os dos docentes e discentes da escola básica envolvidos no projeto. (ARAÚJO, 2015) O suporte teórico a essa discussão pautou-se na perspectiva de uma epistemologia da prática, que, para Tardif (2000, p. 10), seria "o estudo do conjunto dos saberes utilizados realmente pelos professores em seu espaço de trabalho cotidiano para desempenhar sua tarefa".

A partir dessas questões, o principal objetivo do Pibid foi possibilitar aos professores em formação uma visão teórica e prática mais qualificada da questão da inclusão, de forma geral, e das diferentes síndromes e diagnósticos de deficiências, em particular. Para tanto, trabalhou em parceria com uma escola estadual, que tem sido considerada referência no processo de inclusão dos 
alunos com necessidades especiais. Nessa escola, no ano de 2011, das dez turmas do $1^{\circ}$ a $5^{\circ}$ anos, nove tinham alunos com algum comprometimento físico ou intelectual. Além disso, a escola contava com uma sala de recursos para atendimento individualizado a esses alunos.

O trabalho do Pibid se dividiu em duas frentes principais. A primeira teve como objetivo pesquisar as diferentes síndromes e diagnósticos de deficiências dos alunos, articulando a pesquisa teórica ao processo de observação das crianças em processo de inclusão na escola. Nesse processo, ao mesmo tempo em que se estudavam as síndromes, os bolsistas observavam o comportamento e as interações dessas crianças com os colegas e as professoras. A segunda frente pautou-se no planejamento e execução de práticas pedagógicas envolvendo as linguagens oral e escrita, de forma a fomentar a participação e a aprendizagem de todos os estudantes da escola básica, sobretudo os que estavam em processo de inclusão.

Uma das características mais importantes do Pibid é o fato de que ele possibilita que a formação dos graduandos, no caso da Pedagogia, possa ser diretamente articulada com os processos reais da cultura escolar, conforme as colocações de Nóvoa (2009). Para o autor, a dicotomia teoria e prática, com supremacia da primeira, que marca a história da Pedagogia, não permitiu que a prática se transformasse em conhecimento. Assim, a formação de professores continuou a ser dominada mais por referências externas do que por referências internas ao trabalho docente, o que implica uma dificuldade de se compreender que as teorias sobre a questão da inclusão escolar ainda estão por serem construídas no diálogo que a teoria estabelece com os processos reais nas experiências concretas.

O lastro teórico que impulsiona esse campo de estudos ainda se encontra predominantemente na Psicologia - com ênfase em perspectivas biologicistas, individualizantes e assistencialistas -, na Fonoaudiologia e na Neurologia. Todo esse conhecimento, logicamente, ajuda a compreender a pessoa com necessidades especiais e seus processos de aprendizagem. Todavia, quando se discutem metodologias de aprendizagem para elas, esses estudos têm se limitado, geralmente, a procedimentos clínicos e individuais.

O conhecimento teórico sobre as possibilidades pedagógicas da pessoa com necessidade especial em interação com outras crianças sem diagnóstico de deficiência na instituição escolar, e mais especificamente na sala de aula comum, está em processo inicial de 
construção. E, para que seja construído em bases sólidas, precisa estar inserido no âmbito dos estudos relacionados à epistemologia da prática na perspectiva apontada por Nóvoa (2009).

Nessa perspectiva, um dos primeiros desafios do Pibid foi convencer os professores de que o trabalho que os bolsistas do Pibid realizariam com essas crianças não seria feito com uma proposta individual para elas, e sim a partir da busca por inseri-las, de fato, com suas potencialidades e limitações, em atividades coletivas para toda a turma.

Muitas pesquisas têm demonstrado que a inclusão escolar tem se configurado em uma inclusão perversa, uma vez que esses alunos continuam excluídos das atividades escolares e das interações com o grupo. (SAWAIA, 2011) Assim, observou-se que as atividades para pessoas em situação de inclusão geralmente são atividades de séries anteriores e não são pensadas e elaboradas de acordo com as características da síndrome ou deficiência, acreditando-se possivelmente que toda deficiência se caracteriza apenas por um "atraso mental".

A partir desta perspectiva de que a deficiência se caracteriza por um déficit cognitivo, os professores consideravam como estudantes incluídos aqueles "com laudos", como eram chamados os que tinham um laudo médico arquivado na escola, e estudantes "sem laudo", aqueles que, mesmo sem um diagnóstico médico, não acompanhavam o ritmo da turma. Desse modo, o outro desafio enfrentado foi saber exatamente quem eram os estudantes com algum comprometimento físico, intelectual ou sensorial entre os considerados incluídos. A escola dificultava o acesso aos laudos médicos solicitados pelos bolsistas do Pibid e percebia-se total falta de conhecimento dos professores sobre o que versavam esses laudos.

Nessa direção, o conhecimento da escola sobre as crianças consideradas incluídas, suas limitações e potencialidades pedagógicas era restrito, pois se pautava em uma concepção de que essas crianças são incapazes de aprender. A partir desse paradigma, não há nada que a escola possa fazer a não ser garantir o direito à socialização dessas crianças com as outras consideradas com capacidades plenas de aprendizagem. Sob esse prisma, em muitos casos, não havia distinção entre as crianças diagnosticadas com alguma deficiência ou síndrome e as que apresentavam dificuldades de escolarização, sendo todas elas apartadas de grande parte das atividades pedagógicas realizadas com o restante da turma, sobretudo 
as que envolviam os processos de leitura e escrita. Logicamente, havia práticas pedagógicas inclusivas em processo de construção, sendo a própria escola um modelo escolar receptivo e acolhedor a toda e qualquer diferença.

\section{As experiências da Pedagogia e da Psicologia: uma construção polifônica}

Diante das experiências apresentadas anteriormente, uma questão se impõe: quais as especificidades de cada área de conhecimento que poderiam contribuir, de fato, para o processo de inclusão da criança com necessidades especiais?

Os campos de atuação da Pedagogia e da Psicologia têm, salvaguardando as especificidades dos campos de conhecimento, contribuições importantes para a efetivação do projeto de inclusão nas escolas, sobretudo no sentido de colocar em reflexão as possibilidades e limites da política do ponto de vista da implementação nos contextos de prática.

Nesse sentido, o encontro entre os dois campos disciplinares, analisados neste artigo, se dá no entendimento de que, na perspectiva de uma inclusão escolar efetiva, tanto a prática do psicólogo quanto a do pedagogo precisam se constituir a partir do contexto da escola junto com as crianças e demais atores. A atuação não deve se restringir a um conjunto de técnicas, tampouco ao conhecimento sobre diagnósticos e síndromes, questionando-se a hegemonia de um discurso técnico-científico em ambas as áreas de conhecimento e a forma como esses conhecimentos se materializam nas práticas.

Esse discurso hegemônico, técnico-científico, traz consequências para as relações entre os atores institucionais nos espaços educativos, sobretudo atribuindo aos profissionais da área de saúde mais legitimidade para lidar com as questões advindas do processo de inclusão, em detrimento do conhecimento pedagógico em construção, o que significa dizer que se estabelecem relações de poder verticalizadas que marcam o grande desencontro entre modos de pensar/fazer a Psicologia e a Pedagogia.

Assim, as relações entre psicólogos e professores, por sua vez, têm sido hegemonicamente pautadas em relações hierárquicas de poder, tendo em vista a postura autoritária assumida por alguns profissionais do campo da Psicologia frente aos professores. Nessa assimetria, sobressaem conhecimentos pautados em uma 
determinada concepção de ciência em que o discurso biológico atravessa e legitima atuações pautadas na busca de patologias que justifiquem o fracasso escolar, individualizando as soluções para as problemáticas escolares e situando no estudante a responsabilidade pelo frágil desempenho acadêmico. Essa concepção, geralmente, encontra eco entre os professores que veem nessa perspectiva um atenuante para lidar com a forte pressão por resultados satisfatórios por parte de todos os atores, Estado, familiares, direção da escola e sociedade civil.

A Psicologia, na interface com a Educação, precisa balizar seu trabalho a partir do que os professores, no seu fazer e conhecimento prático, técnico e cotidiano a respeito dos alunos, the fornecem. A prática psicológica nas instituições escolares precisa partir, portanto, do campo escolar para a construção de estratégias que venham subsidiar os atores segundo suas demandas. Ao colocar-se na função de especialista, detentor do saber científico, tratando estes sujeitos como universais, desconsidera-se suas singularidades e o conhecimento construído pelos professores nas experiências e práticas com os estudantes nos convívios diários.

Da mesma forma, a Pedagogia, na interface com a Psicologia, precisa acreditar mais em seus processos de construção de um arcabouço pedagógico, que, rompendo com perspectivas teórico-metodológicas padronizadoras e homogeneizantes, considere todas as diferenças inerentes ao agrupamento humano que se forma em uma sala de aula, tendo, no campo de conhecimento da Psicologia, um possível suporte desde que pautado no diálogo e no compartilhar de conhecimentos e experiências, e não o tomando como balizador das ações pedagógicas na escola. Assim:

Para situarmos nosso objeto, é preciso compreendermos, de uma nova maneira, as relações entre os processos psicológicos e os pedagógicos ou, em outras palavras, o papel da educação na construção da subjetividade humana e o papel da subjetividade na construção do processo educacional. (MEIRA, 2000, p. 59)

Nessa mesma ótica, questiona-se que o estudo teórico das síndromes e deficiências por si só seja suficiente para subsidiar as ações do professor na perspectiva de propiciar processos de aprendizagem para os diferentes sujeitos. Esse saber é potencializado ao se articular com os casos reais, com sujeitos reais, uma vez que uma criança é diferente de outra criança, assim como uma criança 
com síndrome de Down, por exemplo, é diferente de outra criança com síndrome de Down.

Diante do exposto, acredita-se que a atuação dos profissionais, em particular do pedagogo e do psicólogo, pode ser potencializada se essas questões forem colocadas em reflexão, sobretudo pelos sujeitos que estão atuando diretamente nos processos concretos de inclusão.

\section{Considerações finais}

A escola deve ser compreendida como um espaço de relações entre sujeitos atravessados por relações de poder. Essa instituição situa-se, ainda, dentro de um contexto sociopolítico específico e é, portanto, afetada pelos valores e relações que são estabelecidos fora do espaço institucional. Analisar os problemas de aprendizagem e de socialização de estudantes no espaço educacional significa considerar sua experiência na escola no entrecruzamento com os vários atores com quem compartilha a experiência dentro e fora da instituição escolar. Partindo desse princípio, a experiência dos sujeitos (adultos e crianças), suas apreensões, seus discursos e estratégias de enfrentamento para os problemas da/na escola podem fazer revelar problemáticas que pertencem ao modo como a escola se configura nos seus preceitos e projeto político, bem como o cenário político-econômico de forma mais ampla.

Diante desse contexto, entende-se que, pelo pouco tempo de implementação das políticas de inclusão nas escolas, tanto na pedagogia quanto na psicologia, uma base de conhecimentos e saberes, que possa vir a dar alguma diretriz ao trabalho destes profissionais, ainda está em processo de construção na interação com os casos concretos do/no cotidiano escolar, embora essa construção seja permanente.

Nesse sentido, acredita-se que é no processo de formação continuada, e na articulação com a área da saúde, em diálogo com as questões e vivências reais da prática pedagógica, que os saberes necessários à inclusão vão se constituindo. Assim, investir na articulação do trabalho do pedagogo e do psicólogo se mostra fundamental na perspectiva de que um traz subsídios para o trabalho do outro sem superposições ou subalternizações. 


\section{Encuentro y desencuentro entre la psicología y la pedagogía en los procesos de inclusión escolar.}

Resumen: Este artículo trae reflexiones sobre la actuación de profesionales de la salud y de la educación en el contexto de la política de inclusión en escuelas brasileñas, considerando la siguiente cuestión: ¿cuál de hecho es el papel del pedagogo y del psicólogo en el proceso de inclusión escolar? A partir de sus experiencias en diferentes proyectos de inclusión escolar de niños y niñas, una, envolviendo estudiantes del curso de psicología de una Universidad de Rio de Janeiro, y otra, con estudiantes del curso de pedagogía, en Minas Gerais, el análisis recae en la discusión sobre las problemáticas que atraviesan las prácticas en el saber cotidiano de las escuelas brasileñas, tanto en sus tensiones así como vislumbrando posibilidades de actuación y de interlocución entre los profesionales de diferentes campos disciplinares, el de la pedagogía y el de la psicología. Desde la perspectiva de la psicología histórico-cultural y la epistemología de la práctica, el análisis de las experiencias presentadas apunta que invertir en la articulación del trabajo del pedagogo y del psicólogo se muestra fundamental en la perspectiva de que un trae subsidios para el trabajo del otro sin superposiciones o subalternizaciones.

Palabras claves: inclusión escolar, psicología, pedagogía.

\section{Agreements and disagreements between psychology and pedagogy in the processes of school inclusion}

Summary: This article presents thoughts based on practice of health and education professionals in the context of inclusion policy in Brazilian schools, considering the following question: what is the role of the pedagogue and the psychologist in the process of school inclusion? Based on two experiences, in different projects of children's school inclusion, one involving students of the Psychology course at a university in Rio de Janeiro and another with students from the Pedagogy course in Minas Gerais, the analysis takes place around the discussion about the issues which go beyond the everyday practices in schools including disagreements in envisioning possibilities of action and interlocution between the professionals of different disciplinary fields, the one of the pedagogy and the one of the psychology. From the perspective of historical-cultural psychology and the epistemology of practice, the analysis of the experiences presented show that investing in the articulation of the work of the pedagogue and the psychologist is fundamental in the perspective that one brings subsidies to the work of the other without overlapping or subalternizations.

Keywords: School inclusion. Psychology.Pedagogy.

\section{Referências}

ARAÚJO, M. J. de G. M. de. A formação de professores inclusivos. A experiência do Programa Institucional de Bolsa de Iniciação à Docência (Pibid) do Curso de Pedagogia da UFSJ. In: CARVALHO-FREITAS, M. N. Inclusão: possibilidades a partir da formação profissional. São João DelRei: Universidade Federal de São João Del-Rei, 2015. 2015. 
BRASIL. Ministério da Educação. Secretaria de Educação Especial (SEESP). Política Nacional de Educação Especial na Perspectiva da Educação Inclusiva. Brasília, DF, 2008.

BRASIL. Lei $n^{0}$ 13.146, de 06 de julho de 2015. Institui a Lei Brasileira de Inclusão da Pessoa com Deficiência (Estatuto da Pessoa com Deficiência). Disponível em: http://www.planalto.gov.br/ccivil_03/_ Ato2015-2018/2015/Lei/L13146.htm. Acesso em: 4 nov. 2019.

BOURDIEU, P. A escola conservadora: as desigualdades frente à escola e à cultura. Educação em Revista, Belo Horizonte, v. 10, p. 3-15, 1989.

DAYRELL, J. A escola como espaço sócio-cultural. In: DAYRELL, J. Múltiplos olhares: sobre educação e cultura. Belo Horizonte: UFMG, 1996.

FOUCAULT, M. Microfisica do poder. Rio de Janeiro: Graal, 1979.

FREIRE, P. Pedagogia da autonomia: saberes necessários à prática educativa. 25. ed. São Paulo: Paz e Terra, 2002.

JOBIM E SOUZA, S.; KRAMER, S. Debate Piaget Vygotsky e as políticas educacionais. Cadernos de pesquisa, São Paulo, n. 77, maio 1991.

MEIRA, M. E. Psicologia escolar: pensamento crítico e práticas profissionais. In: PROENÇA, M.; ROCHA, M. L. da. Psicologia e educação: desafios teórico-práticos. (org.) São Paulo: Casa do Psicólogo, 2000.

MORAES, M.; ARENDT, R. Materialidades e socialidades no cotidiano: múltiplos modos de ordenamento da deficiência visual. In: JOBIM E SOUZA, S. Tecnologias e modos de ser no contemporâneo. Rio de Janeiro: 7 Letras; PUC-RJ, 2010.

NÓVOA, A. Para uma formação de professores construída dentro da profissão. Revista de Educación, La formación de professores de Educación Secundaria, Madri, v. 350, p. 1-10, 2009. Disponível em: http://www. revistaeducacion.educacion.es/re350/re350_09por.pdf.Acesso em: 4 nov. 2008.

SAWAIA, B. B. O sofrimento ético-político como categoria de análise da dialética exclusão/inclusão. In: SAWAIA, B. B. (org.). As artimanhas da exclusão: uma análise ético-psicossocial da desigualdade. 7. ed. Petrópolis: Vozes, 2011.

SCHÖN, D. Formar professores como profissionais reflexivos. In: NÓVOA, A. (coord.) Os professores e sua formação. Lisboa: Dom Quixote, 1992.

TARDIF, M. Saberes profissionais dos professores e conhecimentos universitários: elementos para uma epistemologia da prática profissional dos professores e suas consequências em relação à formação para o magistério. Revista Brasileira de Educação, São Paulo, v. 13, p. 5-24, 2000. 
VYGOTSKY, L. A formação social da mente. São Paulo: Martins Fontes, 1984.

Submetido em 20/03/2019.

Aceito em 07/11/2019. 